\title{
Glucose lowering activities of mombintane I and mombintane II isolated from the leaves of Spondias mombin $\mathrm{L}$
}

\author{
Adediwura A. FRED-JAIYESIMI ${ }^{1,2 *}$, Richard M. WILKINS ${ }^{2}$ and Kio A. $\mathrm{ABO}^{3}$ \\ ${ }^{I}$ Department of Pharmacognosy, Olabisi Onabanjo University, Sagamu Campus. Ogun State ,Nigeria. \\ ${ }^{2}$ Newcastle University, Newcastle-Upon-Tyne, NE1 7RU, UK. \\ ${ }^{3}$ Department of Pharmacognosy, Faculty of Pharmacy, University of Port-Harcourt, Rivers State, Nigeria. \\ *Corresponding author; E-mail: adediwurajaiyesimi@googlemail.com
}

\begin{abstract}
The uses of Spondias mombin Linn in folk medicine as part of recipe for the management and treatment of Diabetes mellitus are well documented. This has been investigated and proven using various experimental models. The aim of this study was to report two isolated compounds from S. mombin leaves probably exhibiting synergistic glucose lowering effects in the in vitro model. The in vitro $\alpha$-amylase inhibitory assay was used to establish the glucose lowering activities of the isolated compounds while, the isolated compounds were determined from the spectra of their MS, IR and proton NMR. It was established that they are sterols with molecular formula $\mathrm{C}_{29} \mathrm{H}_{52} \mathrm{O}_{2}$ and $\mathrm{C}_{29} \mathrm{H}_{50} \mathrm{O}$. The two compounds exhibited a synergistic effect of $61 \% \alpha$ amylase inhibitory activity. This study shows that mombintane I and mombintane II exhibit synergistic effect in lowering blood glucose levels.
\end{abstract}

(C) 2017 International Formulae Group. All rights reserved.

Keywords: Mombintane I, Mombintane II, Glucose lowering, Spondias mombin, Leaves.

\section{INTRODUCTION}

The various uses of the leaves, stem bark and fruits of Spondias mombin L in folk medicine for the treatment of ailments and diseases have been reported (Ayoka et al. 2005; Ayoka et al., 2006) while some of these folk uses have been investigated. The antidiabetic and hypoglyceamic effects of the leaves (Fred-Jaiyesimi and Abo, 2009), seed (Iweala et al., 2011), hypolipidemic and antioxidant activity of the leaves (Nkanu et al., 2016) have been reported. Also, the extract of the leaves of $S$. mombin has been shown to have the ability to reduce labour times and treat hemorrhage (Pakoussi et al., 2013). Furthermore, in male rats the aqueous extract had no effect on the male body weight but increased the weight of the liver (Raji et al., 2000). The active constituents responsible for some of these activities have been isolated 
from the different morphological parts of $S$. mombin. (Fred-Jaiyesimi et al., 2009; Olugbuyiro et al., 2013).

This study aimed at further investigating other compounds present in the leaves of $S$. mombin exhibiting glucose lowering activities.

\section{MATERIALS AND METHODS}

Plant collection and authentication

The leaves of Spondias mombin L were collected form Sagamu, Ogun State and the plant sample was authenticated at the herbarium of the Forestry Research Institute of Nigeria (FRIN) Ibadan and Department of Pharmacognosy, Olabisi Onabanjo University where a voucher specimen number PHS 413 was deposited.

The leaves were shade dried, powdered in an electric blender and stored for further analysis.

\section{Extraction and isolation}

The dried powdered leaves of $S$. mombin were macerated in methanol for 3 days after which it was filtered and the filtrate concentrated in a rotatory evaporator. The dark green extract was applied on a flash column chromatography using silica gel $\mathrm{GF}_{254}$ and fractions eluted with varying polarities of chloroform and methanol. Fractions with similar Rf values on the analytical TLC were pooled together, were tested for antidiabetic activities and the main fraction obtained inhibited the $\alpha$-amylase activity. The fraction which showed most activity was then purified on preparative TLC using Hexane: diethyl ether $(1: 1)$ on Silica gel $\mathrm{GF}_{254}$
$(1000 \mu \mathrm{G}, 20 \mathrm{~cm}$ X $20 \mathrm{~cm})$. The recovered compound was further assayed for $\alpha$-amylase inhibitory activity.

\section{Spectroscopic methods}

The mass spectra and IR were determined using Micromass Autospec $\mathrm{M}$ and Perkin Elmer 1725 on $\mathrm{KBr}$ disc while the ${ }^{1}$ HNMR was carried out using Bruker Avance $300 \mathrm{MHz}$ coupled with fourier transform facility.

\section{Glucose lowering assay \\ The $\alpha$-amylase inhibitory assay methods (Fred-Jaiyesimi et al., 2009b) were adopted to determine the antidiabetic activity of the active fraction at a dose of $50 \mathrm{mg}$ and compared with $\alpha$-amylase inhibitory activity of Acarbose at $5 \mathrm{mg}$.}

\section{RESULTS}

The active fraction at a dose of $50 \mathrm{mg}$ inhibited the activity of the $\alpha$-amylase enzyme by $61 \%$ compared with the $60 \%$ inhibiting effect of acarbose at $5 \mathrm{mg}$ hence, the fraction appears to exhibit a similar effect like Acarbose $(\mathrm{p}<0.05)$ (Figure 1).

The HPTLC of the component in the fraction appeared as a single spot with $\mathrm{Rf}$ value 0.70 in a mobile phase of Toluene/Ethyl acetate/Acetic acid (7:3:0.1). The spot reacted positively to both Lieberman Burchard and Anisaldehyde-Sulphuric acid spray reagents indicating the presence of sterols. However, the proton NMR spectrum of the light green crystal suggested the presence of two sterols with very similar chromatographic characteristics. 


\section{Mombintane I}

EISM 446 [M-H]-, 430 Calc. for $\mathrm{C}_{29} \mathrm{H}_{52} \mathrm{O}_{3}$. ${ }^{1} \mathrm{HNMR}:$ 6.31, 3.65, 3.55, 1.98 , $1.63,1.56,1.45,1.23,1.17,1.07$. 0.93 .

\section{Mombintane II}

EISM: $430[\mathrm{M}-\mathrm{H}]$ - calc. for $\mathrm{C}_{29} \mathrm{H}_{50} \mathrm{O}_{2}$. ${ }^{1} \mathrm{HNMR} \quad(300 \mathrm{MHz}, \quad \mathrm{CDCL} 3, \quad \mathrm{TMS}=$ $0.000 \mathrm{ppm}) 4.40,3.74,3.55,2.26,1.97,1.66$, $1.61,1.56,1.45,1.41,1.36,1.21,1.05,0.93$

The spectra of the component in fraction resembled those previously isolated compounds from the stem bark of S. mombin, Stigmasta-9-en-3,6,7 triol and 3-hydroxy,22epoxystigmastane. (Olugbuyiro et al., 2013).

\section{DISCUSSION}

The ability of compounds from various plant species to inhibit the enzymes responsible for the breakdown of carbohydrate as a means of controlling and treating Diabetes mellitus has been widely reported and documented. The antidiabetic activities of the leaves of $S$. mombin has also been reported in previous studies (Fred-Jaiyesimi and Abo, 2009; Fred-Jaiyesimi et al., 2009a).

In this study, two compounds mombintane I and mombintane II co-eluted have been demonstrated to exhibit ability to inhibit $\alpha$-amylase enzymes responsible for the breakdown of carbohydrate and its absorption. These two compounds with similar Rf value might probably be exhibiting synergistic effect in inhibiting the $\alpha$-amylase enzyme activity by $61 \%$, an effect comparable with that exerted by the reference drug, Acarbose $(60 \%)$.

Previous studies have reported the antidiabetic activities of sterols in both in vivo and in vitro models (Alexander-Lindo et al., 2004; Ali et al., 2006; Fred-Jaiyesimi et al., 2009b; Kotowaroo et al., 2008) by retarding the digestion and absorption of carbohydrate in the digestive tract.

Furthermore, previous studies reported the isolation of these two compounds mombintane I and mombintane II from the stembark of $S$. mombin (Olugbuyiro et al., 2013). The study also reported the combined activity of these compounds in inhibiting Mycobacterium tuberculosis (H37Rv Strain), the causative organism of tuberculosis. (Olugbuyiro et al., 2013).

It therefore shows that the possible synergistic potentials of mombintane I and II might be useful in the treatment of both communicable and non-communicable diseases.

Though, these two compounds have been previously isolated from the stem bark of S. mombin, this is the first time they will be isolated from the leaves as well as reported to exhibit glucose lowering potentials. 


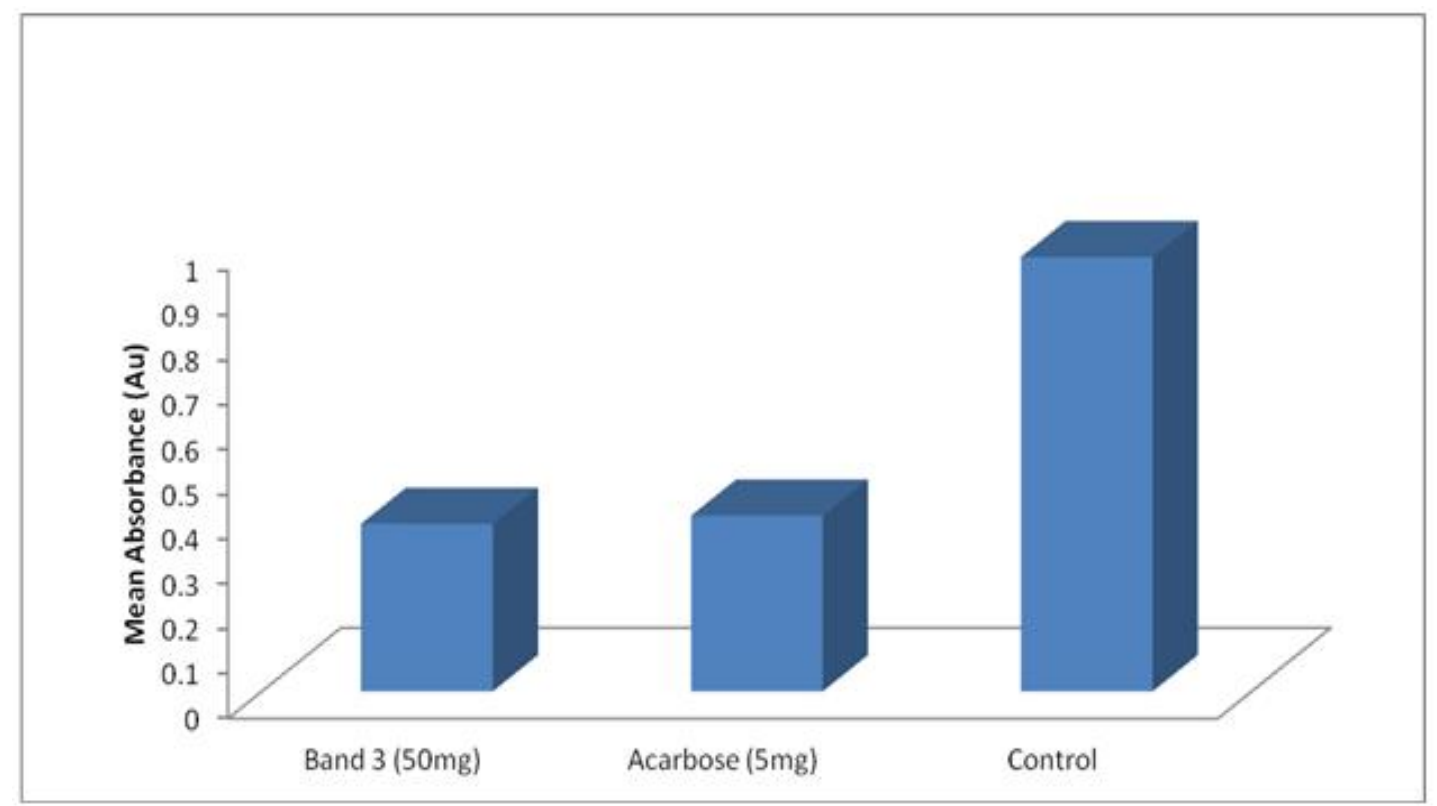

Figure 1: Glucose lowering activity of isolated compounds from band 3 of Spondias mombin leaves.

\section{COMPETING INTERESTS}

Authors do not have any competing interests.

\section{AUTHORS' CONTRIBUTIONS}

AAF-J designed the study and carried out the assay. RMW supervised the study, AAF-J wrote the manuscript and KAA corrected the draft.

\section{ACKNOWLEDGEMENTS}

The authors acknowledge the support of Prof. J.O. Moody in the spectra of this study.

\section{REFERENCES}

Ali H, Houghton PJ, Soumyanath A. 2006. A-amylase inhibitory activity of some Malaysian plants used to treat Diabetes with particular reference to Phyllanthus amarus. J. Ethnopharmacol., 107(3): 449
- 455.4 DOI: https://doi.org/10.1016/j.jep.2006.04.004 Ayoka AO, Akomolafe RO, Iwalewa EO, Ukponwan DE. 2005. Studies on the anxiolytic effect of Spondias mombin L (Anacardiaceae) extracts. Afr. J. Trad. CAM., 2(2): 153 - 165.

Ayoka AO, Akomolafe RO, Iwalewa EO, Akanmu MA, Ukponwan DE. 2006. Sedative, antiepileptic and antipsychotic effects of Spondias mombin L (Anacardiaceae) in mice and rats. $J$. Ethnopharmacol., 103: 166 - 173. DOI : https://doi.org/10.1016/j.jep.2005.07.019

Fred-Jaiyesimi AA, Abo K. 2009. Antidiabetic activity of Spondias mombin extract in NIDDM rats. Pharm Bio., 47(3): 215 - 218. DOI: http://dx.doi.org/ $10.1080 / 13880200802462493$ 
Fred-Jaiyesimi A, Abo K, Wilkins R. 2009. $\alpha$-Amylase inhibitory effect of $3 \beta$-olean12-en-3-yl (9Z)-hexadec-9-enoate isolated from Spondias mombin leaf. Food Chem., 16: 285-288. DOI: https://doi.org/10.1016/ j.foodchem.2009.02.047

Iweala EJ, Oludare FD. 2011. Hypoglycemic effect, biochemical and histological changes of Spondias mombin Linn and Parinari polyandra Benth seeds ethanolic extracts in Alloxan-induced diabetic rats. J. Pharmacol. Toxicol., 6: 101 - 110. DOI: 10.3923/jpt.2011.101.112

Nkanu EE, Jeje SO, Ikpi DE, Ujong GO. 2016. In vivo hypolipidemic and hypoglycemic effects of aqueous extract of Spondias mombin leaves and detoxification of reactive oxygen species in alloxan-induced diabetic rats. Int. $J$. Biol. Chem. Sci., 10(4): 1573 - 1579. DOI:

http://dx.doi.org/10.4314/ijbcsv10i4.10.
Olugbuyiro JAO, Moody JO, Hamann MT. 2013. Phytosterols from Spondias mombin Linn with antimycobacterial activities. Afr J Biomed Res., 16(1): 182-186.

Pakoussi T, Mouzou A, Metowogo K, Agbonon A, Eklu-Gadegbeku K, Aklikokou AA, Gbeassor M. 2013. Effects of Spondias mombin Linn (Anacardiaceae) on rat parturition. Int. J. Biol. Chem. Sci., 7(2): 441 - 446.

Raji Y, Gbadegesin MA, Osonuga OA, Ramat AA, Akinsomisoye OS, Awobajo FO, Olufadekemi TKA, Esegbue Peters PRC, Osonuga IO, Lamidi AF. 2006. Reproductive, haematologic and biochemical profiles of males treated with aqueous extract of Spondias mombin Bark. Inter J Pharmacol., 2: 126-130. DOI: 10.3923/ijp.2006.126.130 